\title{
Chapter 18 \\ Commerce and Conservation in the Crown of the Continent
}

\author{
John S. Waller
}

\begin{abstract}
While railroads figure prominently in U. S. history and culture, their environmental impacts are often overlooked. Here, I describe situations where operation and maintenance of a section of transcontinental railroad in Montana, USA, resulted in high mortality of grizzly bears (Ursus arctos), a threatened species under the U. S. Endangered Species Act, and where proposed avalanche control measures conflicted with the preservation mandates of Glacier National Park. A unique public/private partnership was created to work towards effective solutions to environmental problems. The partnership was successful in decreasing high grizzly bear mortality rates, but less so in finding a consensus on how best to reduce avalanche risk. I suggest that collaborative partnerships, such as that developed here, will be essential to solving future environmental problems associated with railroads.
\end{abstract}

Keywords Avalanche control • Connectivity • Cooperative conservation • Grizzly bear · Highways · Partnerships - Ursus arctos

\section{Introduction}

Railroads hold an important place in U. S. history. They served an important function in settling the west and transporting homesteaders and all the goods they needed to build a life on the frontier. Completed in 1893, the Great Northern was one of the last of the frontier railroads. It penetrated the vast wilderness of northwest Montana, opening an area of scenic wonder to a nation hungry to explore itself. The Great Northern railroad was instrumental in the development of what is now Glacier National Park, constructing numerous grand lodges and chalets that now are themselves historic tourist attractions. These lodges and tourist facilities were small islands of civilization within a largely untamed wilderness.

\footnotetext{
J.S. Waller ( $\square)$

Glacier National Park, West Glacier, MT, USA

e-mail: john_waller@nps.gov

(C) The Author(s) 2017

L. Borda-de-Água et al. (eds.), Railway Ecology,

DOI 10.1007/978-3-319-57496-7_18
} 
Fast-forward 123 years... Glacier National Park is today an island of wilderness surrounded by various levels of development. The grand lodges and chalets have lots of competition for the tourists that arrive in ever-increasing numbers. The golden age of railroads is long past, as most tourists now arrive by automobile or plane rather than train. Still the trains rumble through, carrying every imaginable type of cargo across this mountain vastness.

Railroads have always operated in a unique public/private capacity. Because they required vast capital to construct, and because they provided great benefits to the nation, they were heavily subsidized by the U. S. Government. During the frontier days, these subsidies often came in the form of land grants that could supply the railroads with the resources they needed for construction and that had other values that could help offset the costs of construction. These subsidies required that railroads also be regulated to counter the natural monopolistic tendencies of such an enterprise.

Nevertheless, the railroads amassed tremendous wealth and political power. During the frontier times, railroads were constructed with little consideration of their environmental impacts, and their power was so great that it's unlikely that anyone could have successfully challenged them on those grounds, had they wanted to. Today, railroads still remain powerful entities, but because they serve an important public function, they are also held to public standards of environmental accountability.

This case study is an example of how a railroad, working with government and public partners, discovered ways to uphold its environmental responsibilities by making meaningful contributions to the recovery of the threatened grizzly bear. However, it also describes how tenuous these partnerships can be, and how not all problems are solved through collaboration.

\section{Geographic Location}

The northern-most railroad line in the continental USA is the "hi-line" section of the Burlington Northern-Santa Fe railroad (BNSF, formerly the Great Northern Railroad). It is a primary freight corridor running between Minneapolis, Minnesota, and Seattle, Washington. It also supports the Empire Builder Amtrak passenger line. This railroad line bisects the Rocky Mountains and crosses the Continental Divide at Marias Pass (elevation $1462 \mathrm{~m}$ ). The portion spanning the Continental Divide and lying between East Glacier and West Glacier, Montana, separates two large protected wilderness areas: Glacier National Park to the north $\left(4079 \mathrm{~km}^{2}\right)$, and the Great Bear/Bob Marshall Wilderness Complex to the south $\left(6131 \mathrm{~km}^{2}\right)$. From West Glacier, the railroad follows the Middle Fork of the Flathead River southeasterly to its confluence with Bear Creek, which it then follows northeasterly through the John Stevens Canyon to Marias Pass. East of Marias Pass, the rail line drops down into the South Fork of the Two Medicine River drainage to East Glacier, and crossing into the Blackfeet Indian Reservation. From the Bear Creek/Middle Fork confluence to just west of East Glacier, the railroad is the southern boundary of Glacier National Park (Fig. 18.1). 


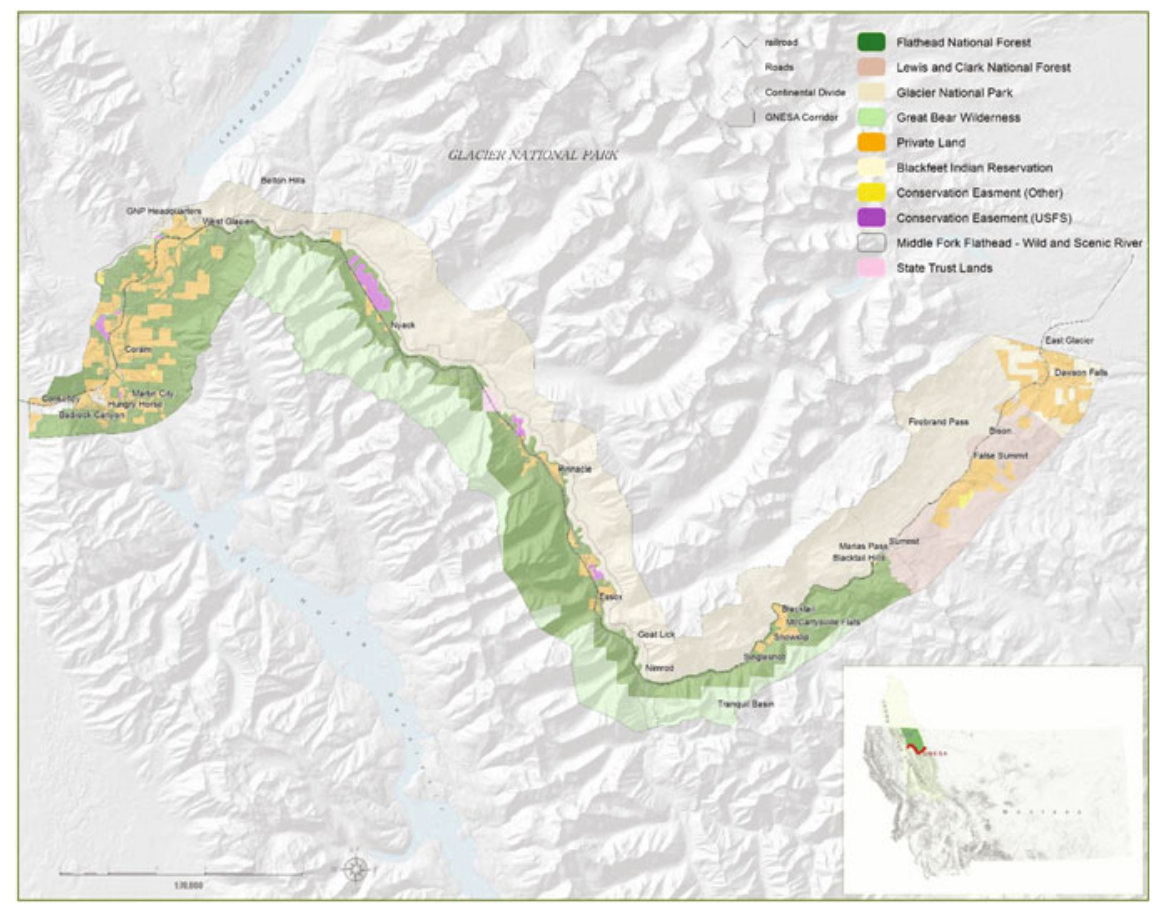

Fig. 18.1 The Great Northern Environmental Stewardship Area between West Glacier and East Glacier, Montana, USA

\section{Land Ownership}

Traveling southeast from West Glacier, the railroad line passes through intermixed public and private lands (Fig. 18.1). The private lands are primarily small ranches and recreational home sites, small communities, and campgrounds. The public lands are primarily managed by the U. S. Forest Service for recreation and timber. Also, U. S. Highway 2 parallels the railroad for its entire length between East and West Glacier, as does a natural gas pipeline and electricity transmission line. This narrow ribbon of railroad, highway, utilities, and private land development form what Servheen and Sandstrom (1993) term a "fracture zone" which is a zone where human development impedes the connectivity of wildlife populations within a natural area.

\section{Ecological Characteristics}

Glacier National Park and the Great Bear/Bob Marshall Wilderness Complex are highly protected federal lands managed for preservation of their natural qualities and for non-motorized recreation. Glacier National Park has been designated a biosphere preserve and a world heritage site by the United Nations (UNESCO). 
Additionally, the Middle Fork of the Flathead River is federally designated as a Wild and Scenic River, which recognizes that it flows on an unmodified flood plain, is ecologically unimpaired, and provides some protection from future development.

The floodplain and its function have been the topic of important ecological research (Harner and Stanford 2003). This area is also home to a number of rare species, including some listed as threatened under the U. S. Endangered Species Act (ESA). These include the grizzly bear (Ursus arctos), Canada lynx (Lynx Canadensis), wolverine (Gulo gulo), and bull trout (Salvelinus confluentus). Other species of note are Rocky Mountain elk (Cervus canadensis), mountain goat (Oreamnos americanus), Rocky Mountain bighorn sheep (Ovis canadensis), moose (Alces alces), mountain lion (Puma concolor), black bear (Ursus americanus), wolf (Canis lupus), and bald eagle (Haliaeetus leucocephalus); in fact, the area retains its entire complement of native fauna with the exception of American bison (Bison bison). This diverse fauna is supported by high floral diversity that arises from the areas location within the transition zone between the Pacific coastal and continental climate regimes.

West of the continental divide, the climate is characterized by cold, wet winters, and cool, moist summers, supporting extensive conifer forests, primarily of Engelmann spruce (Picea engelmannii) and subalpine fir (Abies lasiocarpa). Lodgepole pine (Pinus contortus), Douglas fir (Pseudotsuga menziesii), and western larch (Larix occidentalis) are also well represented. East of the continental

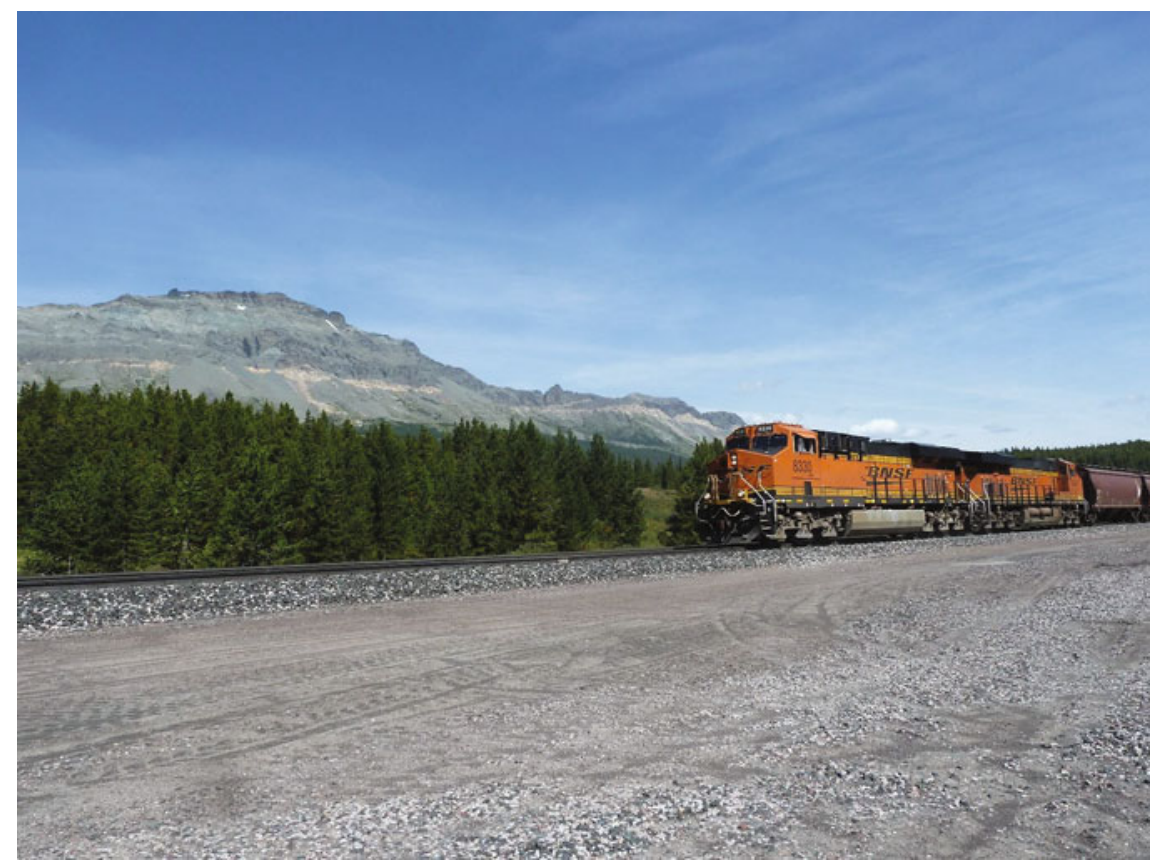

Fig. 18.2 A westbound Burlington-Northern Santa Fe freight train crossing Marias Pass 
divide, the climate is characterized by dry, cold winters and hot, dry summers. Here, conifer forests give way to extensive aspen (Populus tremuloides) park lands and shortgrass prairie (Fig. 18.2). The entire area has been frequently recognized as an important area for wildlife connectivity, for example, the Yellowstone to Yukon conservation initiative (Levesque 2001), the Western Governors Association (2008), and the National Fish and Wildlife Foundation (Ament et al. 2014). The larger ecosystem, which the BNSF rail line crosses has been variously termed the Northern Continental Divide Ecosystem (NCDE; in a grizzly bear recovery plan context), or the Crown of the Continent Ecosystem (in a trans-boundary management context).

\section{Railroad Attributes}

The East Glacier to West Glacier portion of the BNSF railroad line is composed of single and double-track sections, depending on topography. Locomotives are staged along the track to help long freight trains ascend and descend the pass. Freight trains carry a wide variety of goods and materials, especially corn and wheat from the Midwest headed to Pacific export terminals. In recent years, a large volume of crude oil from the Bakken oil fields in North Dakota has been transported as well. Because the railroad traverses extreme mountain topography, it is impacted by snow avalanches, rock slides, floods, heavy snow, and extreme temperatures that can affect rail integrity. Most of the wooden railroad ties over the pass have been replaced with concrete ties to help improve track stability. There are also snow sheds that protect portions of the track from avalanches.

The railroad line in this area generally has a smaller ecological footprint than highways because its width is typically narrower and carries less human traffic. However, as is the case here, railroad lines are typically paired with other developments such as roads and utility corridors. Thus, the cumulative footprint is large. In many areas, wildlife fencing is used to keep animals off rail lines and roads, but in our area, neither the highway nor the railroad line are fenced to exclude wildlife.

\section{A Grizzly Problem Arises}

The railroad operated without much environmental controversy through most of the twentieth century. However, a problem arose during the late 1980s and early 1990s. Between 1985 and 1989, at least 134 cars of corn derailed along a 15-mile section of track west of Marias Pass (Fig. 18.3). Each car carried approximately 3500 bushels of corn so the total amount spilled was 469,000 bushels or nearly 12,000 metric tons. In its haste to repair the tracks and to dispose of the spilled grain, BNSF buried it along its right-of-way. As the buried grain began to decompose, it fermented, producing a strong odor that drew black and grizzly bears 


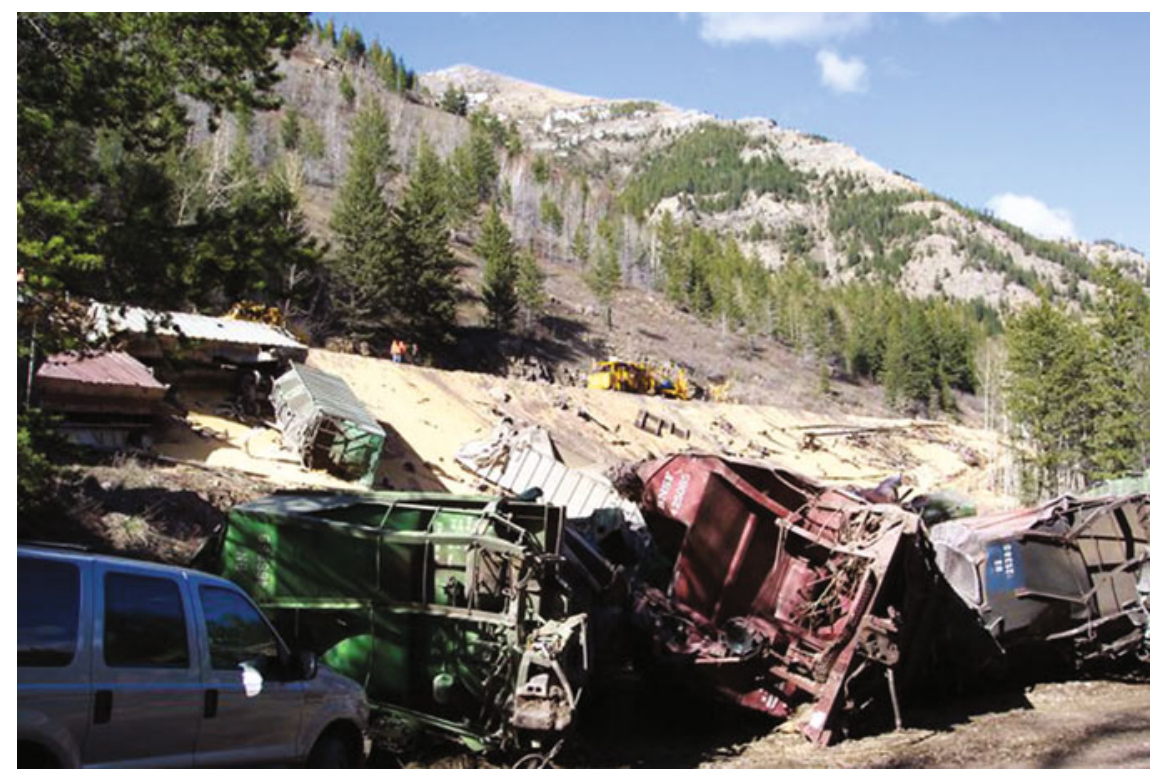

Fig. 18.3 Spilled corn covers the slopes below the tracks during cleanup of a freight train derailment near Marias Pass, Montana, USA

into the site from many kilometers away. One observer claimed to have observed at least 20 different grizzly bears feeding at the site. As the bears began to excavate and consume the fermented grain, some observers believed the bears became intoxicated. Regardless, the feeding bears became highly habituated to the close passage of trains. As a result, between 1985 and 1990, at least 9 grizzly bears were hit by trains and killed. Grizzly bears are listed as a threatened species under the U. S. Endangered Species Act; hence, their deaths during operation of the railroad amounted to an illegal taking under that act.

These grain spills and the resulting deaths of grizzly bears brought increased scrutiny to the frequency and causes of grizzly bear mortalities in the corridor. Bears weren't just dying during grain spills-they were dying at relatively high rates in general. Bears were being struck and killed along the tracks at areas other than grain spills and in conflicts with humans at developed sites. Further investigation revealed that many of the hopper-bottom train cars that carry grain had hopper doors that did not seal well; as a result, grain constantly dribbled out along the tracks and created small piles between the rails whenever the train stopped. Also, as train cars were filled at terminals, grain would accumulate along the tops of the cars, which would then fall off along the tracks as the train headed west. This continuous deposition of grain along the tracks acted as a powerful attractant for bears. Most of the bears found killed by trains had grain in their stomachs.

Much of the rail line through the corridor crosses ungulate winter range and areas grazed by livestock. Wild ungulates and domestic livestock are occasionally 


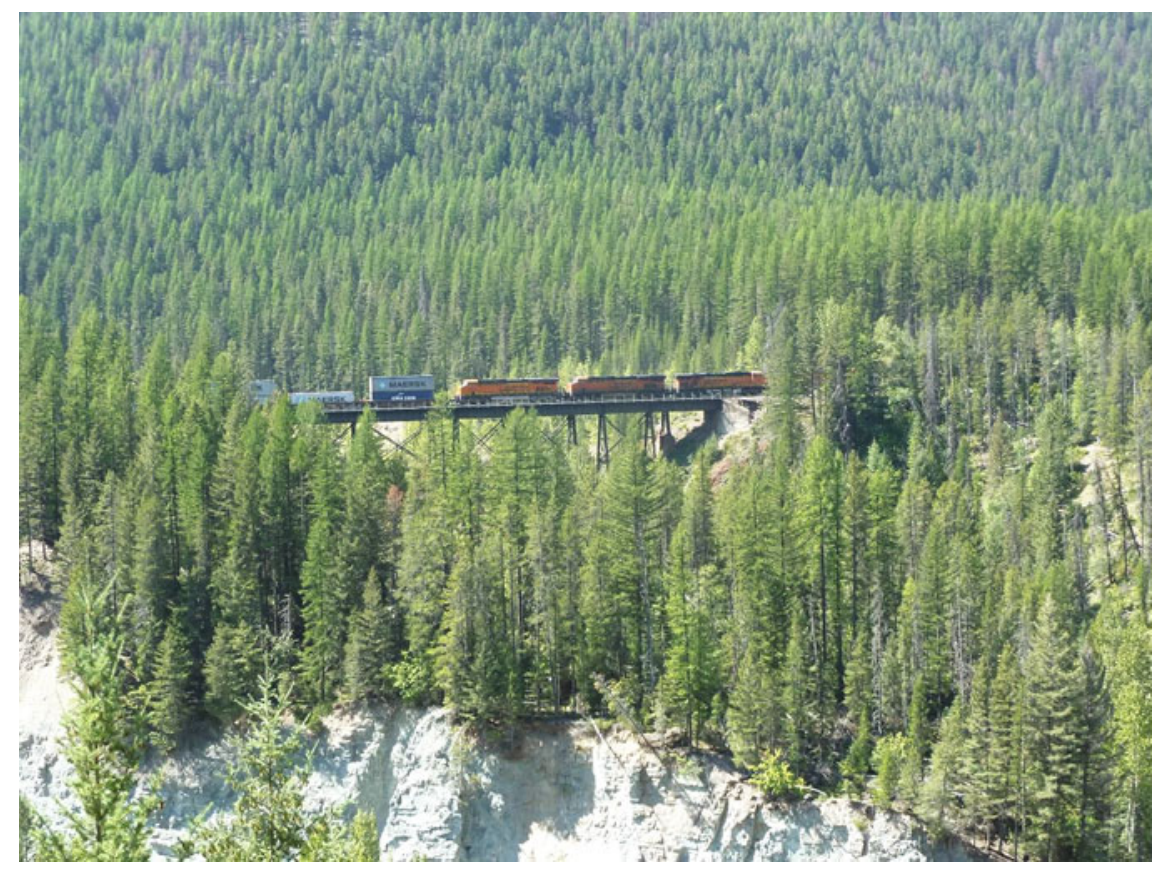

Fig. 18.4 A Burlington-Northern Santa Fe freight train crosses the Sheep Cr. Trestle

struck by trains and their carcasses also become attractants for bears. As bears come to scavenge the remains, they themselves become victims.

A third important source of mortality was associated with trestles. The rail line crosses a number of deeply incised water courses with high trestles (Fig. 18.4). As grizzly bears traveled the tracks in search of grain and carcasses, or just as an easy means of travel, they would utilize these trestles. Occasionally, an oncoming train would overtake bears on the trestle where they could not escape and they would be hit and killed.

\section{Working Towards a Solution}

In 1990, two environmental activist groups threatened to sue the railroad for continuing to kill grizzly bears. During the summer of 1992, railroad operations caused a small wildfire inside Glacier National Park (GNP) that enabled the park to seek damage reparation payment from BNSF. In order to help prevent future grizzly bear mortalities, then-GNP Superintendent Gil Lusk suggested that rather than pay GNP damages for the fire, BNSF establish a special organization to help facilitate solutions to environmental problems in the rail corridor. BNSF agreed and established the rail line between East and West Glacier as a special operating area called 
the Burlington-Northern Environmental Stewardship Area (BNESA), along with an organization to administer its operation.

In the agreement, BNSF and the signatory agencies acknowledged the importance of balancing the interests of commerce, agriculture, transportation, natural resources, and wildlife and acknowledged the nationally significant qualities of the corridor. Specifically, the parties agreed to pay particular attention to the operation and maintenance of the railway because of the areas importance to populations of threatened and endangered species. The parties committed to working cooperatively with affected jurisdictions to plan and implement emergency responses to derailments, including providing and placing emergency response equipment to expedite response times and prevent spilled materials from entering rivers and streams. The agreement tasked wildlife biologists from the Montana Department of Fish, Wildlife, and Parks (MFWP) with determining specific sections of track that were hazardous to grizzly bears or sections where bears frequently crossed the tracks or otherwise congregated. BNSF committed to rapid spill response and placement of cleanup material at key points for ready access to these resources; to strict adherence to operating speed limits, and use of continuous welded rail, welded turnouts, and concrete ties to improve rail integrity; the erection of fences at key locations determined by MFWP wildlife biologists; and special training and educational programs for BNSF personnel working in the corridor conducted by the appropriate agency. The BNESA agreement also established a conservation trust fund to be used for the protection of critical grizzly bear habitat and movement corridors, placement of a grizzly bear management specialist to serve as a coordinator in the area, provide education and resolution of management issues and bear conflicts, and research to evaluate the effectiveness of operational changes and develop new techniques to minimize grizzly bear mortalities. Additional actions implemented by BNSF included the regular use of a vacuum truck that picks up spilled grain along the tracks, and every spring after the snow melts, BNSF crews pick up carcasses along the tracks and dispose of them in safe areas. They have also used motion-sensitive electronic noise makers on trestles to discourage use by bears, and experimented with electric fencing and electric "track-mats". It is difficult to assess the success of these efforts in absolute terms, but we do know that even as the number of bears in the ecosystem has increased substantially (Mace et al. 2012), the numbers of bears hit and killed along the railroad tracks has dropped significantly; only four grizzly bears were killed between 2010 and 2015, compared to the six-year running average of 11.

As the BNESA organization grew, its name was changed to the Great Northern Environmental Stewardship Area (GNESA) to reflect its broader mission and purpose beyond just the BNSF railroad. The GNESA organization grew to include representatives of the more than 20 state, tribal, and federal agencies having land management authority within the GNESA corridor (GNP, U. S. Forest Service, MFWP, Montana Department of Transportation, U. S. Fish and Wildlife Service, Flathead Conservation district, and Blackfeet Indian Nation), private land owners, utilities (Flathead and Glacier Electric Cooperatives, Northwestern Energy), and county officials. Over the next several years, GNESA facilitated additional actions 
to reduce grizzly bear mortalities along the railroad tracks. They helped fund a transition from open garbage containers to bear-resistant models at county refuse sites; worked to establish guidelines for the safe transportation of hazardous materials through the corridor; and facilitated interagency cooperation in planning for responses to accidents involving hazardous materials, including resolution of emergency communications issues.

GNESA has also supported wildlife research in the corridor, including studies of habitat connectivity across the corridor. They worked to preserve local knowledge of wildlife connectivity by hosting workshops that involved citizens who work and live in the corridor, including train engineers, school bus drivers, local law enforcement officials, biologists, and rangers. They helped fund a study of game trail use in the corridor that identified where animals were crossing the highway and railroad (Roesch 2010). This information will be vital, as crossing structures may eventually be required.

BNSF and the U. S. Department of Transportation also supported in-depth research into grizzly bear movement patterns across the corridor. Obtaining fine-scale movement data from grizzly bears was nearly impossible before the advent of satellite global positioning system (GPS) tracking collars in the late 1990s. One of the first studies in the continental U. S. to utilize this technology on brown bears was that of Waller and Servheen (2005), which used a relatively large sample of GPS-collared grizzly bears $(n=42)$, paired with detailed road and traffic counts, to assess the response of grizzly bears to various traffic types and volumes. These researchers found that although the highway and railroad did have measureable effects on the trans-corridor movements of grizzly bears, they still crossed frequently and successfully. Grizzly bears crossing the transportation corridor were faced with traversing both the railroad line and the highway, which closely parallel one another through the GNESA area. The monitored grizzly bears appeared to make behavioral adjustments to daily fluctuations in highway traffic but not for rail traffic. Grizzly bears chose to cross the corridor when highway traffic volumes were lowest, but when rail traffic was the highest. Rail traffic was higher at night because most rail maintenance work is done during daylight hours, thus curtailing daytime freight traffic. Furthermore, freight trains loaded on the coast during the day leave in the evening and arrive in the GNESA area at night, 24-36 h later. It may be that grizzly bears are more easily habituated to rail traffic because it tends to be highly predictable. The consequence, however, is that grizzly bear mortality was much higher on the tracks than on the highway. Between 1980 and 2002, 23 grizzly bears were killed on the tracks in the GNESA corridor, but only two on the highway. The fine-scale movement data did not show that grizzly bears were still feeding on grain accumulations along the railroad tracks, suggesting that grain-control actions were working as intended. Therefore, the authors concluded that the high observed post-grain spill mortality rates were the consequence of high rail traffic volume, low highway traffic volume, and natural grizzly bear movement patterns.

The collaborative environment that fostered the birth of GNESA and innovative problem-solving approaches to environmental issues was recognized as a model for 
other conservation problems throughout the world. In 2008, GNESA was recognized by the U. S. Department of Interior as an exemplary example of collaborative conservation (USDOI 2008). Such collaboration is often the result of the right people being in the right place at the right time. In 2004, an issue arose that would test the limits of the collaborative efforts embodied in GNESA.

\section{An Avalanche of Problems}

On January 28, 2004, heavy snowfall resulted in avalanches in the GNESA corridor that blocked the BNSF railroad for $29 \mathrm{~h}$. These avalanches began in starting zones within the GNP. During the storm, an empty 119-car freight train was struck by an avalanche and derailed. While it was derailed, another avalanche in an adjacent slide path struck the train again, derailing more cars. A third avalanche nearly hit a clean-up crew, and a fourth avalanche hit a truck travelling the highway beneath the railroad. Responding to continued snowpack instability and the need to ensure the safety of its personnel, BNSF requested a special use permit from GNP that would authorize explosive avalanche control in the John Stevens Canyon. After much deliberation, GNP granted a 3-day emergency special use permit, but, as is often the case, moderate weather allowed the snowpack to stabilize, and the avalanche risk abated before any control measures could be implemented.

After the January 2004 incident, BNSF contracted with a company specializing in avalanche control to analyze the avalanche hazard in the canyon. Their report described the avalanche potential in 14 avalanche paths along the railroad in the John Stevens Canyon (Hamre and Overcast 2004). Nine of those paths had some level of protection provided by snow sheds, although seven of them were too short to provide complete protection. Avalanche paths are dynamic, changing over time with changes in vegetation growth. Most of the sheds were constructed around 1900 , so for some of them, the paths had widened or altered position, so that the sheds no longer provided complete protection (Fig. 18.5). The report identified avalanche hazard reduction measures ranging from explosive control to snow shed construction. From the viewpoint of BNSF and their consultants, explosive control was the most expedient and cost-effective means to mitigate the avalanche risk. However, the viewpoint of GNP was quite different.

Glacier National Park is congressionally mandated to protect the park from impairment resulting from human-caused activities. Other legal mandates include the protection of wilderness values (the Wilderness Act of 1964), protection of threatened and endangered species, protection of scenic and cultural resources, and maintenance of visitor enjoyment. The use of explosives generally ran counter to these mandates and were inconsistent with the park's status as a biosphere preserve and world heritage site. In order to evaluate alternative courses of action, GNP prepared an Environmental Impact Statement (EIS) as required by the National Environmental Policy Act of 1970. Four alternatives were evaluated in the EIS: a "no action" alternative, by which no action by BNSF to mitigate avalanche hazard 


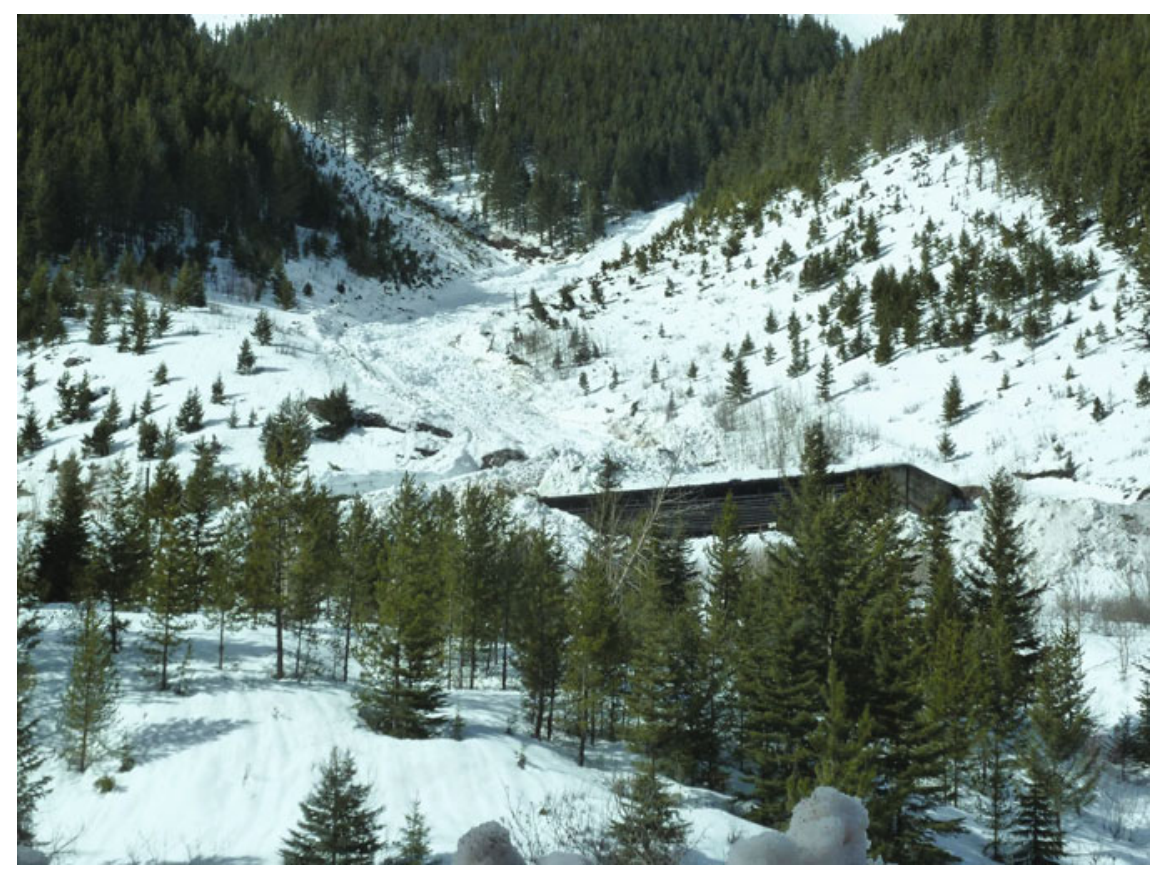

Fig. 18.5 An avalanche partially buries a snow shed on the Burlington-Northern Santa Fe railroad in the John F. Stevens canyon

would be permitted; an alternative where GNP, USFS, and MDOT would recommend constructing and/or modifying snow sheds (the preferred alternative); an alternative similar to the previous alternative but that also included a 10-year special use permit for explosive control during snow shed construction; and, finally, an alternative that allowed explosive avalanche control without concomitant snow shed work (NPS 2008a).

After an extensive analysis and public comment period, GNP selected the preferred alternative and a "record of decision" (ROD) was signed in September 2008. The ROD permitted BNSF to install a weather station and snow depth sensor within GNP, and for BNSF to conduct non-explosive snow stability testing. It allowed the installation of avalanche detection devices, but limited the use of explosives to extenuating emergency conditions where human lives or resources were at risk and after other options, including delays, had been exhausted. The ROD recommended that BNSF construct or modify snow sheds in high-risk slide paths (NPS 2008b).

The search for solutions to the avalanche problem in the GNESA corridor rose quickly to the upper echelons of corporate and government management. As the situation became political, both sides became entrenched in their positions and the collaborative environment of GNESA disappeared. In the end, GNP prevailed in their position but at the cost of some of the close working relationships built within GNESA. Hard feelings remained for some time, and, to date, BNSF has not 
attempted to construct or modify any snow sheds, instead relying on an avalanche forecasting program to mitigate risk. They have approached the park on at least one occasion for a special permit for avalanche control, but usually high-hazard conditions ameliorate rapidly and so the opportunities for explosion control are very limited (Reardon et al. 2004). The BNSF also purchased a "Daisy Bell" device which, when suspended below a helicopter, can test snow stability by directing a blast downward to the snowpack. This technique eliminates many of the disadvantages associated with explosive control. Fortunately, it appears that, as time passes and as personnel changes take place, working relationships are being restored.

\section{What Next?}

The GNESA corridor remains an important locale for commerce and connectivity, and grizzly bears remain an important issue in the corridor. The U. S. Fish and Wildlife Service is working with BNSF to prepare a habitat conservation plan that, under the ESA, will indemnify BNSF against litigation resulting from grizzly bear deaths provided that BNSF continues to implement procedures and practices that work to minimize mortalities. The implementation of the GNESA protocols and continued support of the organization will likely be an important component of that plan.

In general, efforts to control grizzly bear mortality have been successful throughout the ecosystem, and the grizzly bear population rapidly is expanding (Mace et al. 2012). State and federal bear managers are confident about the recovery of the bear population and will likely seek removal of the NCDE grizzly bear from the ESA within the next several years. Collaborative conservation efforts, as embodied by GNESA, have been critical to the attainment of this conservation success.

New issues will continue to surface as development within the corridor continues. Heavy traffic of railroad cars carrying crude oil have been a concern, as has increasing traffic on U. S. Highway 2 (Waller and Miller 2016). As traffic increases, wildlife connectivity across the corridor will diminish to the point where some type of accommodation will have to be made. Crossing structures are the current tool for maintaining connectivity, but other concepts may arise. For example, strategic highway planning might be used to direct higher traffic volumes to better-developed road systems in less ecologically sensitive areas. The avalanche sheds currently used are over 100 years old, in some cases, it might be possible to replace them with new designs that serve to protect the railroad and highway from avalanches and also serve as a crossing structure. Conservation investments of this magnitude will require public/private partnerships and inter-agency collaboration.

New technologies will continue to surface that have the potential to further limit wildlife mortalities and railroads have a responsibility to support the development and application of these technologies. For example, long-range, optical-infrared video alarm systems can warn engineers of wildlife on tracks day or night, far in 


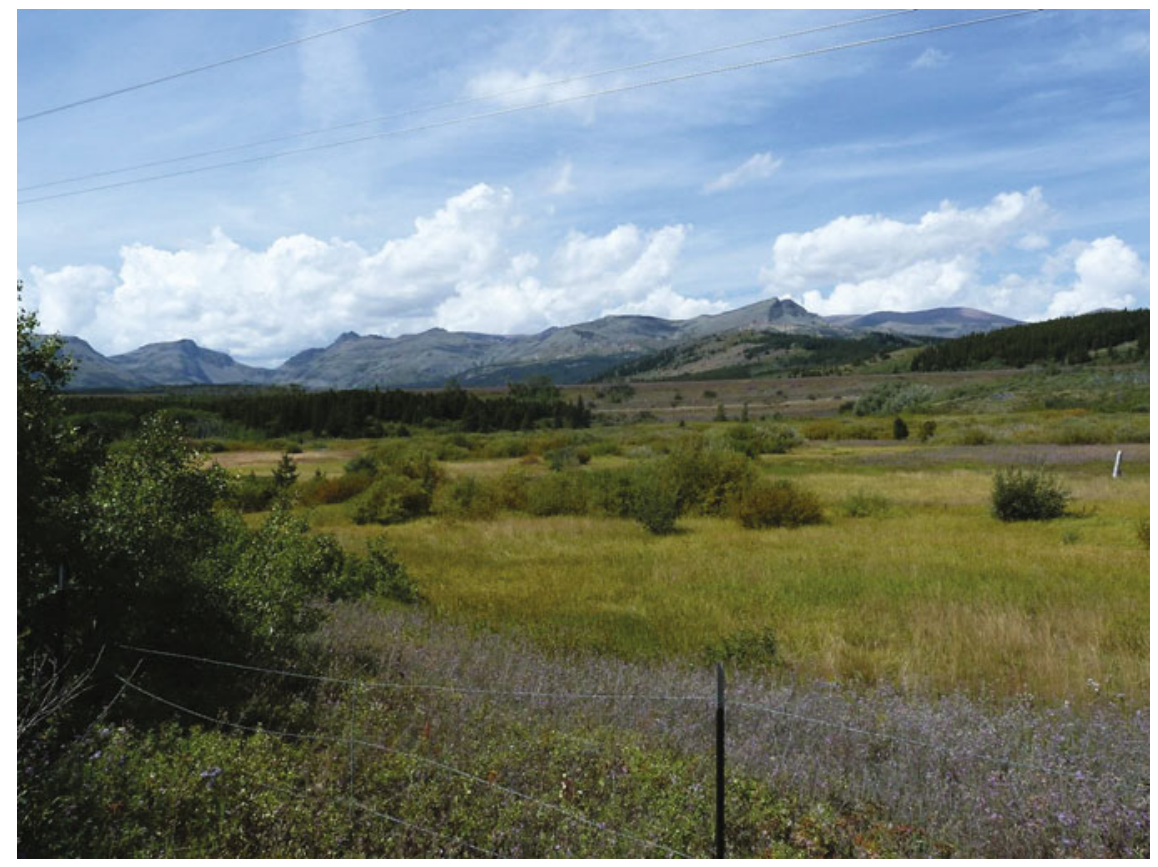

Fig. 18.6 A large cut-and-fill railroad bed completely obstructs natural drainage in Glacier National Park

advance, and long-range acoustic devices or other sonic devices may be able to get animals to move out of harm's way (Babińska-Werka et al.2015; Grey 2015).

As connectivity becomes an issue, so will watershed integrity. When the railroad was constructed, massive cuts and fills were used to bridge drainages (Fig. 18.6), these large fills obstruct the natural terrain, alter natural stream courses, and may need to be removed. Modification of this kind will be very expensive and will probably require public investment.

The success of the GNESA partnership was due, in large part, to the participation of individuals who were unafraid to take risks inside corporate and agency cultures. These individuals were committed to using the GNESA group to seek solutions and to resolve issues at the lowest possible levels. They did not use the media to advance their positions; they worked to get to know one another on a personal level; and they respected each other's different mandates. It also required organizational frameworks that were flexible towards this type of participation and tolerant of the risk that comes with trusting others in other organizations. Future success will demand more of the same from individuals and organizations. Building trust takes time and patience; while some conflict may be inevitable, it is important to accept those situations and move beyond them. Building a robust network of trust requires more than just affinitive trust among key individuals; establishing rational and systems-based trust adds resiliency when personnel turnover changes the group 
dynamic (Stern and Baird 2015). Bridging organizations, such as GNESA, bridge the boundaries between stakeholders that operate at different scales, linking varied constituencies to increase collective capabilities and social capital (Pretty 2003; Pahl-Wostl et al. 2007). With these lessons in mind, the trust and culture will hopefully be in place to allow future collaborative conservation to proceed.

Acknowledgements This study presents the combined contributions of many persons over the course of many years. The author thanks the GNESA partnership for their commitment to environmental stewardship. Major funding for the work described herein was provided by the U. S. Fish and Wildlife Service, U. S. National Park Service, Glacier National Park, and the Federal Highways Administration. Valuable support was provided by the U. S. Forest Service; Montana Department of Transportation; Montana Department of Fish, Wildlife, and Parks; and the Burlington-Northern Santa Fe railroad.

\section{References}

Ament, R., McGowen, P., McClure, M., Rutherford, A., Ellis, C., \& Grebenc, J. (2014). Highway mitigation for wildlife in northwest Montana. Sonoran Institute, Northern Rockies Office, Bozeman, MT, 84 pp.

Babińska-Werka, J., Krauze-Gryz, D., Wasilewski, M., \& Jasińska, K. (2015). Effectiveness of an acoustic wildlife warning device using natural calls to reduce the risk of train collisions with animals. Transportation Research Part D: Transport and Environment, 38, 6-14.

Grey, E. (2015). The underdog: Preventing animal casualties on railways. http://www.railwaytechnology.com/features/featurethe-underdog-preventing-animal-casualties-on-railways-4532957/. Accessed June 12, 2016.

Hamre, D., \& Overcast, M. (2004). Avalanche risk analysis: John Stevens Canyon, Essex, Montana. Unpublished Report, Chugach Adventure Guides, LLC., Girdwood, AK, 80 pp.

Harner, M. J., \& Stanford, J. A. (2003). Differences in cottonwood growth between a losing and a gaining reach of an alluvial floodplain. Ecology, 84, 1453-1458.

Levesque, S. L. (2001). The Yellowstone to Yukon conservation initiative: reconstructing boundaries, biodiversity, and beliefs. In: Reflections on water: New approaches to transboundary conflicts and cooperation (pp. 123-162). Cambridge: MIT Press.

Mace, R. D., Carney, D. W., Chilton-Radandt, T., Courville, S. A., Haroldson, M. A., Harris, R. B., et al. (2012). Grizzly bear population vital rates and trend in the Northern Continental Divide Ecosystem, Montana. The Journal of Wildlife Management, 76, 119-128.

National Park Service. (2008a). Avalanche hazard reduction by Burlington Northern Santa Fe Railway in Glacier National Park and Flathead National Forest, Montana. Final Environmental Impact Statement.

National Park Service. (2008b). Avalanche hazard reduction by Burlington Northern Santa Fe Railway in Glacier National Park and Flathead National Forest, Montana. Record of Decision.

Pahl-Wostl, C., Craps, M., Dewulf, A., Mostert, E., Tabara, D., \& Taillieu, T. (2007). Social learning and water resources management. Ecology and Society, 12, 2007.

Pretty, J. (2003). Social capital and the collective management of resources. Science, 302, $1912-1914$.

Reardon, B. A., Fagre, D. B., \& Steiner, R. W. (2004, September). Natural avalanches and transportation: A case study from Glacier National Park, Montana, USA. In Proceedings of the International Snow Science Workshop (pp. 19-24). 
Roesch, M. J. (2010). Identifying wildlife crossing zones for the prioritization of highway mitigation measures along US Highway 2: West Glacier, MT to Milepost 193. Thesis, University of Montana.

Servheen, C., \& Sandstrom, P. (1993). Ecosystem management and linkage zones for grizzly bears and other large carnivores in the northern Rocky Mountains in Montana and Idaho. Endangered Species Technical Bulletin, 18(3), 10-13.

Stern, M. J., \& Baird, T. (2015). Trust ecology and the resilience of natural resource management institutions. Ecology and Society, 20, 14.

US Department of Interior. (2008). Press release. Available from https://www.doi.gov/sites/doi. gov/files/archive/news/archive/08_News_Releases/080421d.html

Waller, J. S., \& Miller, C. S. (2016). Increasing traffic volumes on US Highway 2. Intermountain Journal of Sciences, 21 (in press).

Waller, J. S., \& Servheen, C. (2005). Effects of transportation infrastructure on grizzly bears in Northwestern Montana. Journal of Wildlife Management, 69, 985-1000.

Western Governors Association. (2008). Western Governors' Association wildlife corridors initiative report. Available from http://www.westgov.org/images/dmdocuments/wildlife08.pdf. Accessed July, 2016.

Open Access This chapter is licensed under the terms of the Creative Commons Attribution 4.0 International License (http://creativecommons.org/licenses/by/4.0/), which permits use, sharing, adaptation, distribution and reproduction in any medium or format, as long as you give appropriate credit to the original author(s) and the source, provide a link to the Creative Commons license and indicate if changes were made.

The images or other third party material in this chapter are included in the chapter's Creative Commons license, unless indicated otherwise in a credit line to the material. If material is not included in the chapter's Creative Commons license and your intended use is not permitted by statutory regulation or exceeds the permitted use, you will need to obtain permission directly from the copyright holder.

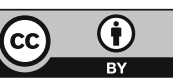

